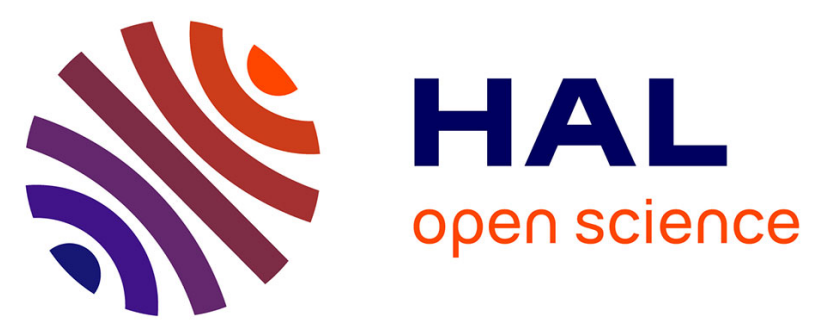

\title{
Ultra-high performance liquid chromatography coupled to triple quadrupole mass spectrometry detection of naturally occurring thiouracil in urine of untreated livestock, domesticated animals and humans
}

Julie Vanden Bussche, Lynn Vanhaecke, Yoann Deceuninck, Klaas Wille, Karen Bekaert, Bruno Le Bizec, Hubert de Brabander

\section{To cite this version:}

Julie Vanden Bussche, Lynn Vanhaecke, Yoann Deceuninck, Klaas Wille, Karen Bekaert, et al.. Ultrahigh performance liquid chromatography coupled to triple quadrupole mass spectrometry detection of naturally occurring thiouracil in urine of untreated livestock, domesticated animals and humans. Food Additives and Contaminants, 2011, 28 (02), pp.166. 10.1080/19440049.2010.544681 . hal-00662387

\section{HAL Id: hal-00662387 https://hal.science/hal-00662387}

Submitted on 24 Jan 2012

HAL is a multi-disciplinary open access archive for the deposit and dissemination of scientific research documents, whether they are published or not. The documents may come from teaching and research institutions in France or abroad, or from public or private research centers.
L'archive ouverte pluridisciplinaire HAL, est destinée au dépôt et à la diffusion de documents scientifiques de niveau recherche, publiés ou non, émanant des établissements d'enseignement et de recherche français ou étrangers, des laboratoires publics ou privés. 


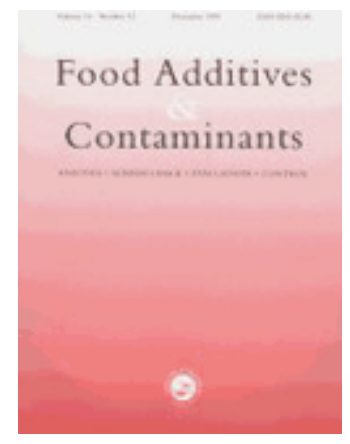

Ultra-high performance liquid chromatography coupled to triple quadrupole mass spectrometry detection of naturally occurring thiouracil in urine of untreated livestock, domesticated animals and humans

\begin{tabular}{|r|l|}
\hline Journal: & Food Additives and Contaminants \\
\hline Manuscript ID: & TFAC-2010-341.R1 \\
\hline Manuscript Type: & Original Research Paper \\
\hline Methods/Techniques: & Chromatography - LC/MS, Clean-up, Exposure, Extraction \\
\hline Additives/Contaminants: & Drug residues - hormones \\
\hline Food Types: & Animal feed, Vegetables, Processed foods, Animal feedingstuffs \\
\hline & \\
\hline
\end{tabular}

\section{SCHOLARONE ${ }^{\text {M }}$ Manuscripts}


1 Ultra-high performance liquid chromatography coupled to triple

2 quadrupole mass spectrometry detection of naturally occurring thiouracil

3 in urine of untreated livestock, domesticated animals and humans

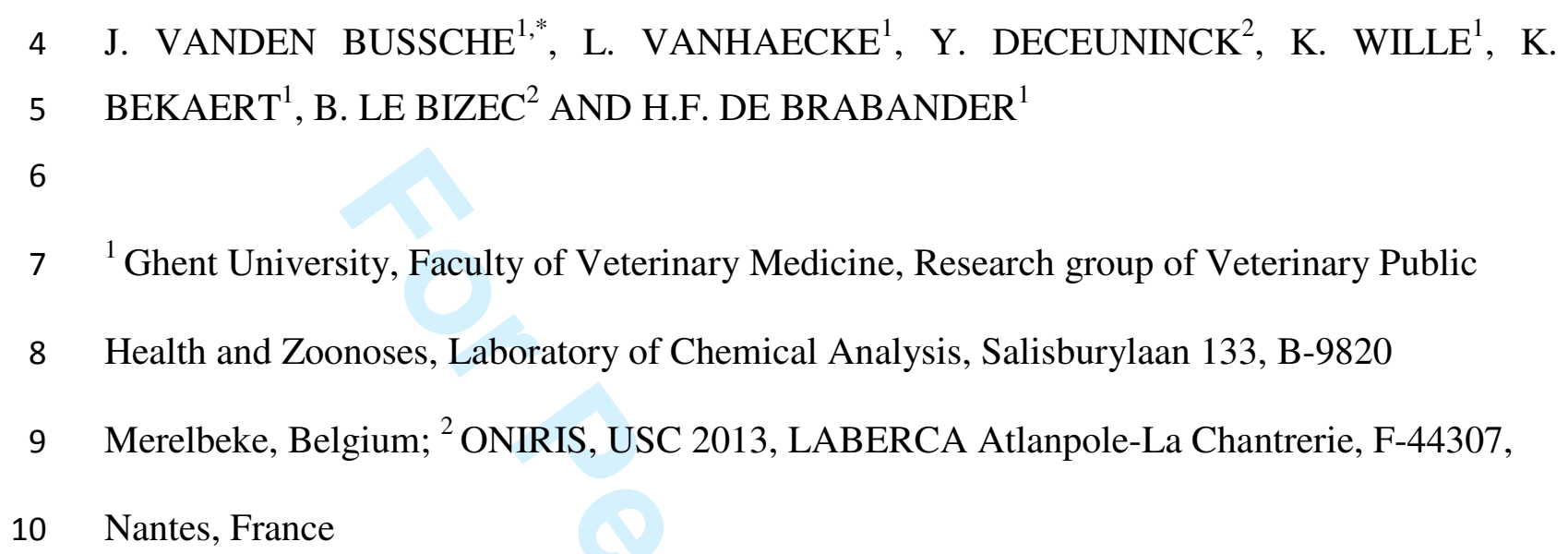




\section{Abstract}

12

Thiouracil (TU) belonged to the xenobiotic thyreostats, which are growth-promoting agents, illegally used in animal production. Recently, it has been reported that thiouracil is suspected to have a natural origin. The EURL guidance paper (2007) acknowledged this, by stating that thiouracil concentrations below $10 \mu \mathrm{g} \mathrm{L}^{-1}$ might have a natural origin derived from Brassicaceae consumption. The present research aimed at endorsing this possible natural occurrence. Urine samples of animals (livestock and domesticated) with known and unknown clinical backgrounds were analysed for thiouracil with a newly developed ultra-high performance liquid chromatography coupled to triple quadrupole mass spectrometry analysis method without derivatisation. In addition, a small-scale 9-day human experiment with Brassicaceae vegetables was performed to investigate if this natural prevalence could be extrapolated to the human population. The untreated animals had thiouracil concentrations below $10 \mu \mathrm{g} \mathrm{L}^{-1}$ acknowledging the alleged natural occurrence of thiouracil. As for the humans, in $66.7 \%$ of the urine samples thiouracil was found above the $\mathrm{CC}_{\alpha}$ of $2.2 \mu \mathrm{g} \mathrm{L}^{-1}$. However the correlation with the Brassicaceae diet proved not significant $(\mathrm{p}=0.095)$. Nevertheless, these results clearly demonstrate the natural occurrence of thiouracil in urine of animals and humans. The exact origin of this natural thiouracil trace still needs to be identified.

Keywords: U-HPLC; triple quadrupole mass analyser; thiouracil; thyreostats; naturally occurring; urine 


\section{Introduction}

Thiouracil (TU) belonged to the group of xenobiotic thyreostats. These are orally active drugs, which upon administration disturb the normal metabolism of the thyroid gland by inhibiting the production of the hormones triiodothyronine and thyroxine (Courtheyn et al. 2002; De Brabander 1984). This goitrogenic activity may be attributed to the presence of a thiocarbamide group (Mackenzie and Mackenzie 1943). In livestock, the administration of thyreostats results in a considerable live weight gain, mainly caused by increased water retention in edible tissue and augmented filling of the gastro-intestinal tract (Kotter et al. 1959; Derblom et al. 1963). Consequently, these growth-promoting agents negatively affect the meat quality of treated animals. In addition, some xenobiotic thyreostats such as thiouracil (TU) are listed as compounds with teratogenic and carcinogenic properties and thus pose a possible human health risk (International Agency for Research on Cancer) (IARC 2010). These arguments led in 1981 to a ban on the use of thyreostats for animal production in the European Union (European Community 1981).

In recent years, questions have been raised with regard to the status of thiouracil. The onset of this was given in 2006 by Pinel et al., who reported a correlation between the supplementation of a Brassicaceae diet to cattle and the presence of TU in bovine urine. This was considered as a first indication that thiouracil might have a natural origin. In December 2007, the European Union Reference Laboratories (EU-RLs) acknowledged this possibility by posting a guidance paper stating a recommended concentration $(\mathrm{RC})$ of $10 \mu \mathrm{g} \mathrm{L}^{-1}$ for thiouracil in urine (EU-RL 2007). According to their opinion, all values below this RC could be linked to a natural origin. In general, for detecting thiouracil in urine at these low-level concentrations, LC-MS analysis based on the protocol of Pinel et al. (2005) was performed. Prior to the analysis of TU, which is a small, ampotheric, and relatively polar molecule, derivatisation with 3iodobenzylbromide (3-IBBr) was conducted to aid in extraction and detection (Pinel et al. 

2005; Lõhmus et al. 2009; Vanden Bussche et al. 2009). However, the use of a derivatisation step may lead to possible false-positive results. To this purpose, an U-HPLC-MS/MS analysis procedure has recently been developed, allowing the detection of thiouracil in urine without derivatisation. This method proved able to detect TU well below the RC of $10 \mu \mathrm{g} \mathrm{L}^{-1}$, with a decision limit $\left(\mathrm{CC}_{\alpha}\right)$ and detection capability $\left(\mathrm{CC}_{\beta}\right)$ of $2.2 \mu \mathrm{g} \mathrm{L}^{-1}$ and $3.0 \mu \mathrm{g} \mathrm{L}^{-1}$, respectively (Vanden Bussche et al. 2010). In addition, this newly developed method, without derivatisation, significantly reduced the likelihood of false-positive results, and designed to assist in investigating the natural occurrence of TU.

The aim of the present study was to establish the presence of thiouracil in urine of untreated livestock, this in the low-level range $\left(<10 \mu \mathrm{g} \mathrm{L}^{-1}\right)$. Therefore, field samples of various species were analysed using our newly developed method, to exclude possible false-positive results. If thiouracil is detected in these field samples, it concerns most likely, as stated by the EU-RL guidance paper, a contamination of natural origin derived from feed (EU-RL 2007). This poses yet another question, can this natural prevalence be extrapolated to the human population, and if so, is this than correlated to any dietary habits, possibly elucidating the natural origin? Therefore, this study also aimed at unravelling the presence of thiouracil in human urine and investigated a possible correlation with the administration of a Brassicaceaecontaining diet. The generated data may also be of value for indirect risk assessment, regarding the body burden of TU. To this purpose, a small-scale experiment with six healthy volunteers was conducted, during which the volunteers were asked to consume Brassicaceae vegetables. The sampled urines were subsequently analysed for the presence of thiouracil by means of ultra-high performance liquid chromatography coupled to triple quadrupole mass spectrometry (U-HPLC-MS/MS) (Vanden Bussche et al. 2010). 


\section{Materials and Methods}

\section{Reagents and chemicals}

The chemical standard 2-thiouracil (TU) and deuterated internal standard 6-propyl-2thiouracil-D5 (PTU-D5) were obtained from Sigma-Aldrich (St. Louis, MO, USA) and Toronto Research Chemicals Inc. (Toronto, Canada), respectively. Stock solutions were prepared in methanol at a concentration of $200 \mathrm{ng} \mu \mathrm{L}^{-1}$. Working solutions were prepared by 200x and 2000x dilutions in methanol ( $1 \mathrm{ng} \mu \mathrm{L}^{-1}$ and $0.1 \mathrm{ng} \mu \mathrm{L}^{-1}$, respectively). When necessary, sonication was applied to ensure the complete dissolution of the substances. Solutions were stored in dark glass bottles at $7{ }^{\circ} \mathrm{C}$.

Reagents were of analytical grade when used for extraction, and of Optima® LC-MS grade when used for U-HPLC-MS/MS analysis. They were obtained from VWR International (Merck, Darmstadt, Germany) and Fisher Scientific (Loughborough, UK), respectively.

Phosphate buffer, dissolved in deionised water, was made up from $0.5 \mathrm{M} \mathrm{Na}_{2} \mathrm{HPO}_{4} \cdot 2 \mathrm{H}_{2} \mathrm{O}$ and $0.5 \mathrm{M} \mathrm{KH}_{2} \mathrm{PO}_{4}$, adjusted to a $\mathrm{pH}$ of 7 . For extraction purposes, the required amount of phosphate buffer, $\mathrm{pH} 7$, was saturated with $1 \%$ of DL-dithiothreitol (DTT, purity 99\%, Sigma-Aldrich, St. Louis, MO, USA).

\section{Instrumentation}

Separation of thyreostatic compounds was carried out at $35^{\circ} \mathrm{C}$ on an Acquity HSS T3 column (High Strength Silica particles) $(1.8 \mu \mathrm{m}, 100 \mathrm{~mm} \times 2.1 \mathrm{~mm}$, Waters, Milford, MA, USA), coupled to an Accela U-HPLC pumping system (Thermo Fisher Scientific, San Jose, USA). In addition, an Acquity UPLC in-line filter $(2.1 \mathrm{~mm}, 0.2 \mu \mathrm{m}$, Waters $)$ was used to improve analytical column lifetime. The mobile phase constituted of $0.1 \%$ aqueous formic acid and $0.1 \%$ formic acid in methanol, and was pumped at a flow rate of $0.3 \mathrm{~mL} \mathrm{~min}^{-1}$. Optimized separation of the analytes was obtained using a linear gradient starting with a mixture of $95 \%$ aqueous formic acid and 5\% formic acid in methanol. After 1.65 min the amount of acidified 
108

109

110

111

112

113

114

115

116

117

118

119

120

121

122

123

124

125

126

127

128

129

130

131

132

133

methanol was increased to $100 \%$ in $5.2 \mathrm{~min}$ and kept there for $0.5 \mathrm{~min}$. Finally, the column was allowed to re-equilibrate for $2 \mathrm{~min}$ at initial conditions, this before each run. Analysis was performed on a triple quadrupole mass analyzer (TSQ Vantage, Thermo Fisher Scientific, San Jose, USA), fitted with a heated electrospray ionisation (HESI II) source operating in positive ion mode. The following working conditions were applied: spray voltage at $3.5 \mathrm{kV}$; vaporizer and capillary temperature at 370 and $300{ }^{\circ} \mathrm{C}$, respectively; sheath and auxiliary gas at 40 and 20 arbitrary units (a.u.), respectively; cycle time of $0.8 \mathrm{~s}$. Argon pressure in the collision cell (Q2) was set at 1.5 mTorr and the mass resolution at the first (Q1) and third (Q3) quadrupole was set at 0.7 Da at full width at half maximum (FWHM). Precursor ion, Slens RF amplitude, and collision energy (CE) in Q2 were optimized individually per compound (Table 1). Quantification and confirmation data for thiouracil were acquired in the selected reaction monitoring (SRM) acquisition mode. The transitions followed for TU and PTU-D5 are also displayed in Table 1. Instrument control and data processing were carried out by means of Xcalibur Software (2.0.7, Thermo Fisher Scientific, San José, USA). Additionally, data was statistically interpreted using ANOVA (S-PLUS, Seattle, WA, USA), level of significance was $5 \%$.

\section{Samples livestock and domesticated animals}

The urine samples were divided into two groups. The first group comprised bovine $(n=222)$, porcine $(n=63)$ and ovine urine samples $(n=19)$ obtained from veterinary sampling in light of the European residue control plan of Belgium and Norway. Upon arrival at laboratory, samples were stored at $-20{ }^{\circ} \mathrm{C}$, and thawed before analysis. The second group consisted of animals (seven porcine, one bovine, one equine, and one canine urine sample) housed at the Faculty of Veterinary Medicine (Ghent, Belgium), with a known clinical background. All samples, taken in a non-invasive manner by a veterinarian, were stored at $-20{ }^{\circ} \mathrm{C}$.

Prior to analysis, the samples were thawed and subsequently centrifuged for $10 \mathrm{~min}$ at $4000 \times$ $\mathrm{g}$, aliquots of $1 \mathrm{~mL}$ were used for the analytical procedure. To each sample, $50 \mathrm{ng}$ of internal 
134 standard (PTU-D5) was added, to obtain a final concentration of $50 \mu \mathrm{g} \mathrm{L}^{-1}$. As for the spiked 135 samples, a standard solution $\left(0.1\right.$ or $\left.1.0 \mathrm{ng} \mathrm{L}^{-1}\right)$ of thiouracil was added.

\section{Human experiment}

138 A small-scale 9-day study $\left(\mathrm{D}_{0}-\mathrm{D}_{8}\right)$, which consisted of a control and test period that every 139 volunteer had to endure, was performed with healthy female $(n=3)$ and male volunteers $(n=$ $1403)$, aged 27-33 years old. No pre-selection was conducted because a control period $\left(\mathrm{D}_{0}-\mathrm{D}_{2}\right)$ 141 was included. During this period, all volunteers were asked to refrain from any Brassicaceae 142 vegetables or derivatives (e.g. mustard and rapeseed oil) consumption to foresee a natural 143 baseline level and obtain a certain degree of volunteer screening. No other restrictions were 144 imposed on the diet. This experimental design was based on two different studies both dealing 145 with the conversion of glucosinolates after ingestion of a Brassicaceae vegetables (Getahun 146 and Chung 1999; Rouzaud et al. 2004). During the test period $\left(\mathrm{D}_{3}-\mathrm{D}_{5}\right)$, processed 147 Brassicaceae vegetables (e.g. cauliflower, broccoli, and savoy cabbage) were provided to the 148 volunteers and they were asked to consume a minimum of $150 \mathrm{~g}$ at dinner. This was followed 149 by a 3-day control period $\left(\mathrm{D}_{6}-\mathrm{D}_{8}\right)$, during which the volunteers were asked for a second time 150 to refrain from any Brassicaceae consumption as a follow-up to monitor the residual 151 concentration of thiouracil (Getahun and Chung 1999). Urine samples were collected twice a 152 day by the volunteers, this during the whole experiment, and immediately frozen $\left(-20{ }^{\circ} \mathrm{C}\right)$ 153 upon sampling. This pilot study supplied commercially available food products in normal 154 physiological quantities, and urine collection occurred in a non-invasive manner. Therefore, 155 no authorization from the medical ethical committee was required (Ros et al. 2007).

\section{Sample cleanup and U-HPLC-MS/MS analysis}

158 The analytical protocol describing the sample clean-up and U-HPLC-MS/MS analysis has 
160 was reduced by $1 \%$ DTT at $\mathrm{pH} 7$, this under denaturating conditions $\left(30 \mathrm{~min}, 65{ }^{\circ} \mathrm{C}\right)$.

161 Afterwards, a liquid/liquid extraction was performed with ethyl acetate. This was followed by

162 evaporation under nitrogen and dissolution of the dried extract (A/B, 90/10), with subsequent

163 injection onto the U-HPLC system.

164

165 Results and discussion

166 Thiouracil in animal urine

167 In the framework of the national control plan of Belgium and Norway, our Laboratory

168 (Ghent University, Belgium) has frequently received urine samples from livestock for the 169 routine analysis of thyreostats. These obtained urines, subsequently analysed never exceeded 170 the recommended concentration for TU of $10 \mu \mathrm{g} \mathrm{L}^{-1}$. Nevertheless, $61.3 \%$ of bovine urine 171 samples had levels of TU below the RC, for porcine urine this was $96.3 \%$, and for ovine 172 urine $57.9 \%$ of the samples. The clinical background of these animals was unknown. Illegal 173 administration for growth-promoting purposes however, seemed highly unlikely at these low 174 concentrations (De Brabander 1984; Heeremans et al. 1998) and the possibility of a natural 175 origin more plausible.

177 Next, urine sampled from different species with a thoroughly annotated clinical background, 178 and no history of thyreostatic drug administration, was analysed. The experiment comprised 179 seven porcine, one bovine, one equine, and one canine urine sample. All samples, besides 180 the urine originating from the mare, displayed traces of thiouracil below $5 \mu \mathrm{g} \mathrm{L}{ }^{-1}$. Thiouracil 181 was identified according to the criteria of retention time, monitored transitions, and ion 182 ratios as set by the EC/2002/657 (European Community 2002). Additionally, a co183 chromatographic experiment was conducted to ascertain the presence of TU. Therefore, all 184 untreated urines underwent a second analyses upon addition of TU at $5 \mu \mathrm{g} \mathrm{L}^{-1}$ (Figure 1). 185 When TU was added an increase in signal was observed at the retention time corresponding 
to TU, confirming the identity of the analyte. This implies that thiouracil, i.e. below $10 \mu \mathrm{g} \mathrm{L}^{-}$ 1, was detected in urine of different animal species, who never received any thyreostatic treatment. Moreover, the collected urine samples were analyzed with U-HPLC-MS/MS, significantly reducing the likelihood of possible false-positive results. Therefore, it may be concluded that thiouracil has a natural origin, most likely originating from the feed source (Pinel et al. 2006). These data, because of the incompleteness of possible influencing parameters, such as age and sex of the animal, type of feed, were not investigated for significant differences within the different species. Further research should however be performed to this purpose.

\section{Thiouracil in human urine}

After submitting all urine samples to U-HPLC-MS/MS analysis (Vanden Bussche et al. 2010), it became clear that thiouracil was excreted by all healthy volunteers (Figure 2). In $66.7 \%$ of the samples, concentrations higher than the $\mathrm{CC}_{\alpha}$ value $\left(2.2 \mu \mathrm{g} \mathrm{L}{ }^{-1}\right)$ were reached. By including two blank periods in the beginning and at the end of the treatment period, during which volunteers were asked to refrain from Brassicaceae vegetables and derivatives consumption, it was intended to display the elimination kinetics of thiouracil in human urine, as demonstrated by Pinel et al. (2006) in bovine urine. However, a correlation between the presence of thiouracil in the urine and the Brassicaceae-rich diet could not be observed. Moreover, no significant differences in detected TU concentrations $(p>0.05)$ were found between the blank periods and the Brassicaceae period, although a p-value of 0.095 was obtained. Additionally, it needs to be highlighted that the measured concentrations of TU for

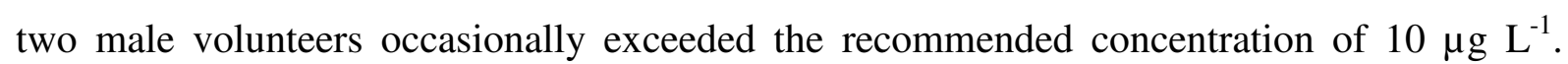
Because of these unexpected results, co-chromatography was conducted on some samples, with spike levels of $5 \mu \mathrm{g} \mathrm{L}^{-1}$ of TU to confirm its presence (Figure 3). Moreover, six samples were re-analysed by LC-MS with the 3-IBBr derivatisation protocol (Pinel et al. 2005), by 
212 two different laboratories (Lab. of Chemical Analysis, Ghent university, Belgium and 213 LABERCA, ONIRIS, Nantes, France), which confirmed the obtained results and 214 concentration levels. To the best of our knowledge this study is the first to report the presence 215 of thiouracil in human urine.

216

All six volunteers were healthy subjects, with no record of a thyroid disease or thyreostatic treatment. Because of the high prevalence $(66.7 \%)$ of TU in the analysed urines, the presence appears to be intake-related. However the contamination source comprised more then only Brassicaceae vegetables and derivatives, which was enforced by the presence of TU in urine derived from the blank period $\left(\mathrm{D}_{0}-\mathrm{D}_{2}\right)$. The additional sources of the contamination could however not be identified. The above mentioned results clearly indicate the natural origin of thiouracil, that was detected in human urine.

\section{Conclusions}

In this work the thyreostatic compound, thiouracil was detected in the urine of untreated animal species, livestock as well as a domesticated animals, this below the recommended concentration of $10 \mu \mathrm{g} \mathrm{L}^{-1}$. Traces of thiouracil below the recommended concentration are accepted by the European Union of Reference Laboratories as contaminations of natural origin. In our study the alimentation between the animals differed and was not controlled, therefore the contamination source of these traces could not be identified.

Even more, the obtained results were transferable to the human population. A small-scale 233 experiment indicated the presence of TU in human urine, this in $66.7 \%$ of the samples 234 analysed. Noteworthy was that the values for two male volunteers sometimes even exceeded 235 the recommended concentration of $10 \mu \mathrm{g} \mathrm{L}^{-1}$. As for the contamination source, the 236 Brassicaceae-rich diet did enforce the presence of the analyte, however in a non-significant 
237 way $(\mathrm{p}=0.095)$. This provided a clear indication that the Brassicaceae diet was not the sole

238 source of contamination for the naturally occurring thiouracil detected in human urine.

239 Finally, from these results it can be concluded that the alleged xenobiotic thyreostat, 240 thiouracil can occur naturally. Up till now, its exact origin remains unknown, but evidence 241 points towards a nutritional origin. Future work will focus on the elucidation of this exact 242 source. In light of this manuscript, another question that requires proper investigation has 243 surfaced with respect to: the impact of this low-level naturally occurring thiouracil trace on 244 the functionality of the thyroid gland. Does it affect the thyroid hormone profile and as such 245 may impose to a possible health risk? Or on the other hand, could thiouracil possibly be a 246 biomarker indicating a perturbated function of the thyroid gland? At this point these questions 247 remain unanswered and further investigation regarding the body burden of naturally occurring 248 TU is required.

250 Acknowledgements

251 The authors wish to acknowledge all volunteers for their efforts during the trial. Also thanks 252 to M. Naessens and L. Dossche for their practical assistance. 


\section{References}

Courtheyn D, Le Bizec B, Brambilla G, De Brabander HF, Cobbaert E, de Wiele AV, Vercammen J, De Wasch K. 2002. Recent developments in the use and abuse of growth promoters. Anal. Chim. Acta 473: 71-82.

Derblom H, Johansson H, Nylander G. 1963. Thyroid hormone activity and gastrointestinal function, an experimental study in the rat. Acta Chir. Scand. 10: 1-5.

European Union Reference Laboratory. 2007. EURL guidance document: EURLs view on state of the art analytical methods for national residue control plans. Available from: http://www.rivm.nl/bibliotheek/digitaaldepot/crlguidance2007.pdf.

De Brabander HF. 1984. Bepalingsmethoden voor thyreostatica in biologisch materiaal. Thesis, Ghent University, Belgium.

European Community. 1981. Council Directive 81/602/EC. Off. J. Eur. Commun. L 222: 3233.

European Community. 2002. Council Decision 2002/657/EC. Off. J. Eur. Commun. L 221: 836.

Heeremans A, Ermens L, De Wasch KK, Van Peteghem C, De Brabander HF. 1998. Elimination profile of methylthiouracil in cows after oral administration. The Analyst 123: $2629-2632$.

International Agency for Research on Cancer. IARC monographs on the evaluation of carcinogenic risks to humans. Last updated Augustus 2010. Available from: http://monographs.iarc.fr/ENG/Classification/index.php.

Kotter L, Terplan G, Schulz J. 1959. Biological demonstration of inhibitors in foodstuff of animal origin. Arch. Lebensmittelhyg. 10: 145-152.

Lõhmus M, Kallaste K, Le Bizec B. 2009. Determination of thyreostats in urine and thyroid gland by ultra high performance liquid chromatography tandem mass spectrometry. J. Chromatogr. A 1216: 8080-8089.

Mackenzie CG, Mackenzie JB. 1943. Effect of sulfonamides and thioureas on the thyroid gland and basal metabolism. Endocrinology 32: 185-193.

Pinel G, Bichon E, Pouponneau K, Maume D, Andre F, Le Bizec B. 2005. Multi-residue method for the determination of thyreostats in urine samples using liquid chromatography coupled to tandem mass spectrometry after derivatisation with 3iodobenzylbromide. J. Chromatogr. A 1085: 247-252. 
287 Pinel G, Mathieu S, Cesbron N, Maume D, De Brabander HF, Andre F, Le Bizec B. 2006. 288 Evidence that urinary excretion of thiouracil in adult bovine submitted to a cruciferous 289 diet can give erroneous indications of the possible illegal use of thyrostats in meat 290 291 Ross MM, Sterk SS, Verhagen H, Stalenhoef AFH, De Jong N. 2007. Phytosterol 292 293 294 Vanden Bussche J, Noppe H, Verheyden K, Wille K, Pinel G, Le Bizec B, De Brabander HF. 295 296 297 298 299 consumption and the anabolic steroid boldenone in humans: A hypothesis piloted. Food Addit. Contam. 24: 679-684. 2009. Analysis of thyreostats: A history of 35 years. Anal. Chim. Acta 637: 2-12.

Vanden Bussche J, Vanhaecke L, Deceuninck Y, Verheyden K, Wille K, Bekaert K, Le Bizec B, De Brabander HF. 2010. Development and validation of an ultra-high performance liquid chromatography tandem mass spectrometry method for quantifying thyreostats in urine without derivatisation. J. Chromatogr. A 1217: 4285-4293. 


\section{Figure captions}

301

302 Figure 1: SRM chromatogram of (a) a bovine urine, and (b) the same urine spiked with $5 \mu \mathrm{g}$ $303 \mathrm{~L}^{-1}$ of thiouracil, after U-HPLC-MS/MS analysis.

304

305 Figure 2: Graphic representation of the mean concentration of thiouracil $\left(\mu \mathrm{g} \mathrm{L}^{-1}\right)$, with error 306 bars representing the standard error of the mean detected, in feminine (P1-3) and masculine 307 (P4-6) human urine, during a 9-day experiment that included two blank periods and a 308 Brassicaceae-rich diet period.

309

310 Figure 3: SRM chromatogram of (a) a human urine, and (b) the same urine spiked at $5 \mu \mathrm{g} \mathrm{L}{ }^{-1}$ 311 of thiouracil by U-HPLC-MS/MS analysis. 


\section{Page 15 of 18}

Food Additives and Contaminants

Table 1: Collected SRM transitions and compound specific MS parameters (product ions in bold were used for quantification purposes).

\begin{tabular}{lccccc}
\hline \multicolumn{1}{c}{ Analyte } & $\begin{array}{c}\mathrm{tR} \\
(\mathrm{min})\end{array}$ & $\begin{array}{c}\text { Precursor ion } \\
(\mathrm{m} / \mathrm{z})\end{array}$ & $\begin{array}{c}\text { Product ion } \\
(\mathrm{m} / \mathrm{z})\end{array}$ & $\begin{array}{c}\text { S-lens } \\
(\mathrm{RF} \text { amplitude })(\mathrm{V})\end{array}$ & $\begin{array}{c}\text { Collision energy } \\
(\mathrm{eV})\end{array}$ \\
\hline \multirow{4}{*}{ Thiouracil } & & & $\mathbf{1 1 2 . 1}$ & & 15 \\
& \multirow{3}{*}{1.55} & 129 & $\mathbf{8 4 . 1}$ & 49 & 27 \\
& & & 60.1 & & 34 \\
& & & 57.1 & & 37 \\
Propyl-thiouracil D5 $^{\mathrm{a}}$ & 5.42 & \multirow{2}{*}{176.1} & $\mathbf{1 5 9 . 2}$ & 62 & 17 \\
& & & $\mathbf{1 1 7 . 2}$ & & 28 \\
& & & 66.1 & & 34 \\
\hline
\end{tabular}

${ }^{\text {a }}$ Internal standard. 

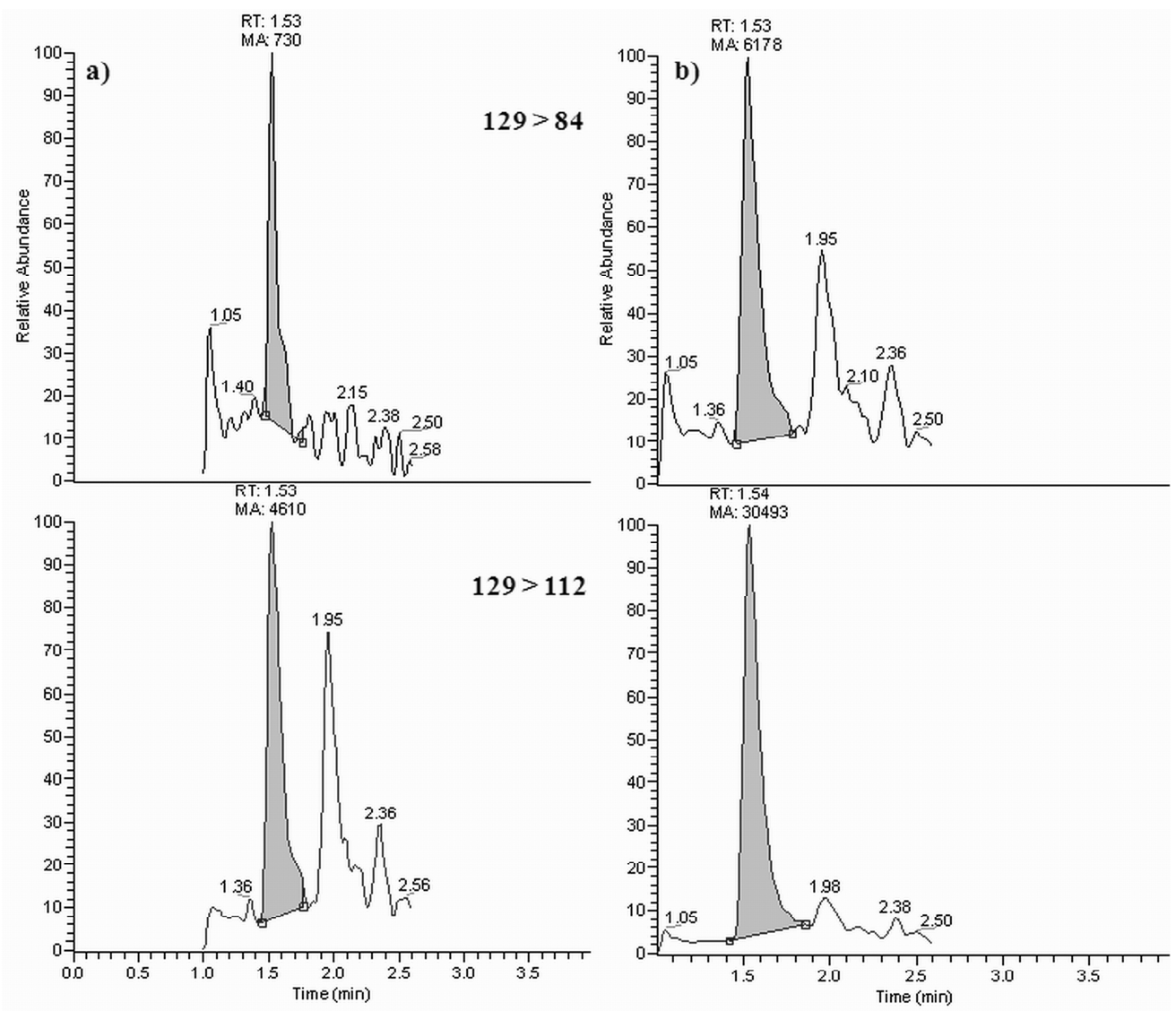

Figure 1: SRM chromatogram of (a) a bovine urine, and (b) the same urine spiked with $5 \mu \mathrm{L} \mathrm{L}^{-1}$ of thiouracil, after U-HPLC-MS/MS analysis. $200 \times 173 \mathrm{~mm}(600 \times 600$ DPI $)$ 
1

2

3

4

5

6

7

8

9

10

11

12

13

14

15

16

17

18

19

20

21

22

23

24

25

26

27

28

29

30

31

32

33

34

35

36

37

38

39

40

41

42

43

44

45

46

47

48

49

50

51

52

53

54

55

56

57

58

59

60

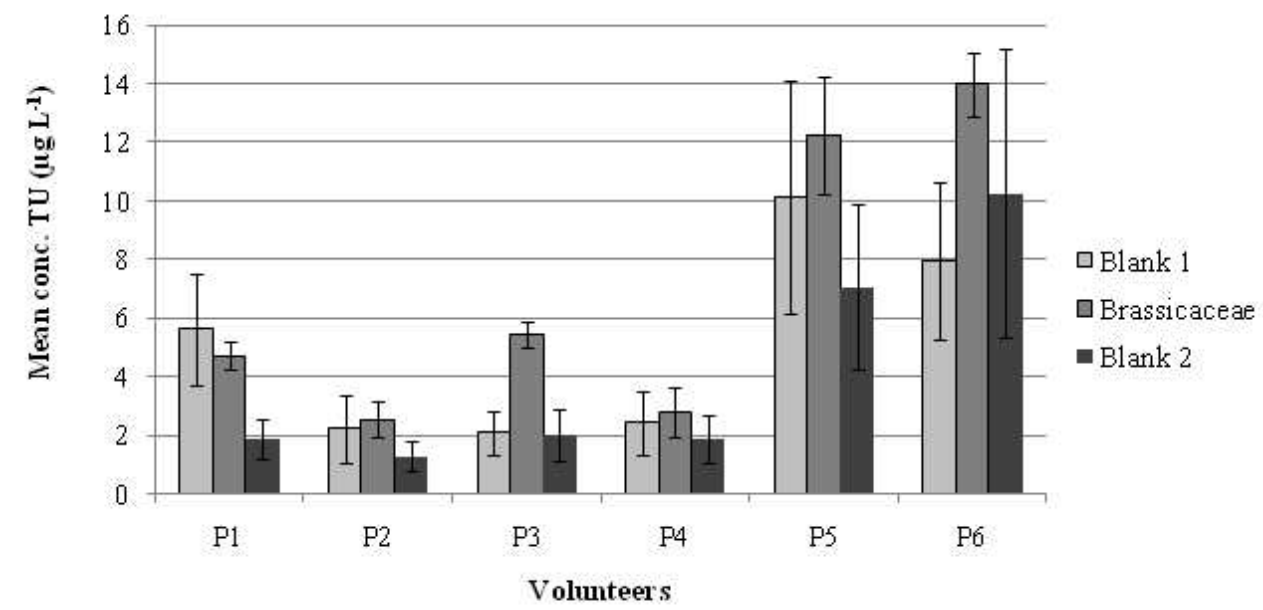

Figure 2: Graphic representation of the mean concentration of thiouracil $\left(\mu \mathrm{L} \mathrm{L}^{-1}\right)$, with error bars representing the standard error of the mean detected, in feminine (P1-3) and masculine (P4-6) human urine, during a 9-day experiment that included two blank periods and a Brassicaceae-rich diet period.

$55 \times 29 \mathrm{~mm}(300 \times 300 \mathrm{DPI})$ 

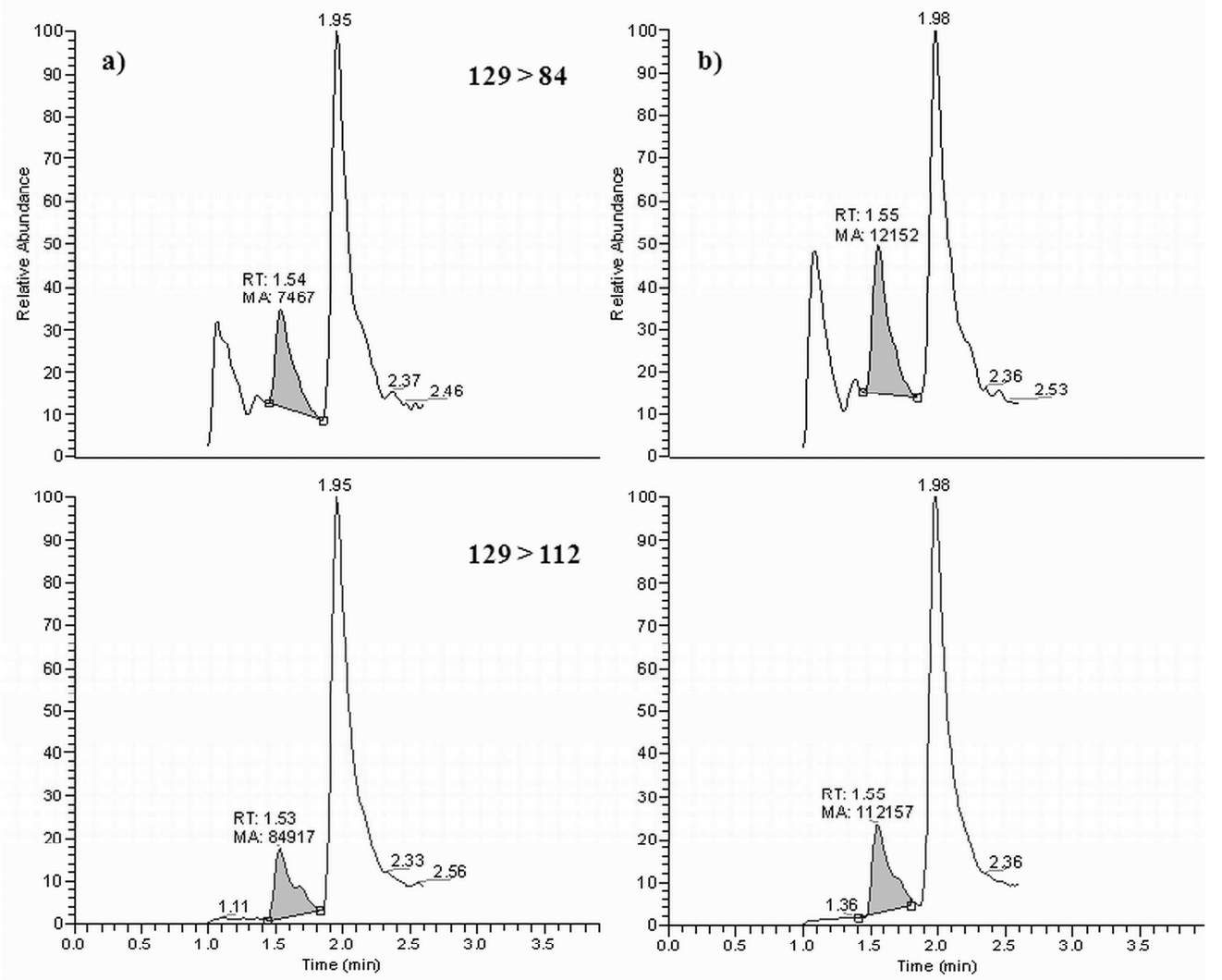

Figure 3: SRM chromatogram of (a) a human urine, and (b) the same urine spiked at $5 \mu \mathrm{g} \mathrm{L}^{-1}$ of thiouracil by U-HPLC-MS/MS analysis. $210 \times 173 \mathrm{~mm}(600 \times 600 \mathrm{DPI})$ 